\title{
The percentage of egg yolk in the freezing media affects mouflon (Ovis musimon) epididymal sperm cryosurvival
}

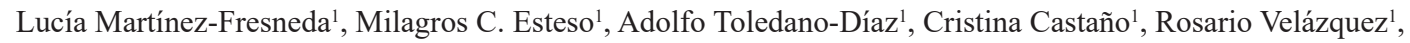 \\ Antonio López-Sebastián ${ }^{1}$, Paloma Prieto ${ }^{2}$, Francisco A. García-Vázquez ${ }^{3}$ and Julian Santiago-Moreno ${ }^{1}$ \\ ${ }^{I} I N I A$, Dept. Reproducción Animal, Avda. Puerta de Hierro km 5.9, 28040 Madrid, Spain. 2 Junta de Andalucía, Consejería de Medio Ambiente y \\ Ordenación del Territorio, D.T. Jaén, 23009 Jaén, Spain. ${ }^{3}$ Universidad de Murcia, Fac. Veterinaria, Dept. Fisiología. 30100 Murcia, Spain.
}

\begin{abstract}
Sperm cryopreservation protocols are not well defined in many wild species such as the mouflon. The aim was to study the effect of different concentrations of EY on mouflon epididymal sperm cryosurvival. Samples were collected by the flushing method and cryopreserved by the conventional freezing technique in straws using a TEST (TES, Tris, glucose) $5 \% \mathrm{v} / \mathrm{v}$ glycerol medium containing either $6 \% \mathrm{v} / \mathrm{v}(\mathrm{n}=16)$ or $12 \% \mathrm{v} / \mathrm{v}(\mathrm{n}=13)$ clarified EY. The membrane integrity, acrosome integrity, motility, and morphological abnormalities were assessed in fresh and frozen/thawed samples. Fresh sperm quality parameters did not differ between groups except for the acrosome integrity that was lower in the TEST- $6 \%$ EY than in the TEST-12\% EY group $(88.9 \pm 2.1 \%$ vs $94.7 \pm 0.8 \%)$. Membrane integrity $(31.6 \pm 4.6 \%$ vs $11.6 \pm 4.5 \%)$, total motility $(32.8 \pm 4.6 \%$ vs $17.2 \pm 5.6 \%)$, progressive motility $(13.3 \pm 2.7 \%$ vs $6.1 \pm 2.9)$ were higher in frozen-thawed sperm with TEST-6\% EY than with TEST-12\% EY $(p<0.05)$. Other motility parameters such as curvilinear velocity, straight-line velocity, average path velocity and amplitude of lateral head displacement were also higher $(p<0.05)$ in frozenthawed sperm with TEST-6\% EY. Frozen-thawed acrosome integrity $(85.1 \pm 3.3 \%$ vs $91.9 \pm 2.3)$ and morphological abnormalities $(34.0 \pm 3.7 \%$ vs $29.1 \pm 3.6 \%)$ did not differ between extenders. In conclusion, high EY concentration had detrimental effects on postthaw quality parameters, therefore the use of TEST based extender containing $6 \%$ EY is recommended for the cryopreservation of mouflon epididymal sperm.
\end{abstract}

Additional keywords: cryobank; hunting resource; reproductive technologies; wild sheep.

Abbreviations used: CASA (computer-assisted sperm analysis system); E/N (eosin-nigrosin staining); EY (egg yolk); HOST (hypo-osmotic swelling test); NAR (normal acrosome ridge); PI (propidium iodide); PNA-FITC (fluorescein isothiocyanate-conjugated peanut agglutinin).

Authors' contributions: Conceived, designed and performed the experiments: JSM, MCE and ALS. Acquisition and analysis of samples: LMF, MCE, ATD, CC, RV and ALS. Analyzed the data: LMF, FAGV. Administrative, technical, and material support: PP. Wrote the paper: LMF, MCE, FAGV, JSM. All authors read and approved the final manuscript.

Citation: Martínez-Fresneda, L.; Esteso, M. C.; Toledano-Díaz, A.; Castaño, C.; Velázquez, R.; López-Sebastián, A.; Prieto, P.; García-Vázquez, F. A.; Santiago-Moreno, J. (2018). Short communication: The percentage of egg yolk in the freezing media affects mouflon (Ovis musimon) epididymal sperm cryosurvival. Spanish Journal of Agricultural Research, Volume 16, Issue 3, e04SC04. https://doi.org/10.5424/sjar/2018163-13268

Received: 04 Apr 2018. Accepted: 03 Oct 2018.

Copyright (C) 2018 INIA. This is an open access article distributed under the terms of the Creative Commons Attribution 4.0 International (CC-by 4.0) License.

Funding: European Union, Horizon 2020 Marie Sklodowska-Curie Action (REPBIOTECH 675526 EU-H2020 MSCA); MINECO, Spanish Government (AGL2014-52081-R).

Competing interests: The authors have declared that no competing interests exist.

Correspondence should be addressed to Julian Santiago-Moreno: moreno@inia.es

\section{Introduction}

The mouflon (Ovis musimon), a wild ancestor of domestic sheep, is widely distributed in Europe and has an important hunting interest. The recovery of epididymal sperm samples from death animals followed by its cryopreservation is an important source of genetic material that can be preserved in genetic resource banks for conservation purposes, but also for improving the stock on hunting reserves. Nevertheless, sperm cryopreservation protocols are not well defined yet in many wild species such as the mouflon. The egg yolk (EY) is a common component of semen extenders of several species. It has been suggested that the main protective effect of EY from freezing damage is related with the interaction of the low-density lipoproteins (LDL) of the EY with some seminal plasma proteins such as the Binder of Sperm proteins (Manjunath, 2012). Also, the presence of EY in semen extenders not only prevents the lipid efflux from the sperm plasma membrane, but stimulates cholesterol and choline phospholipids gain (Bergeron 
et al., 2004). The use of EY in ram sperm diluents prevents ultrastructural changes such as the swelling of the acrosome during the cooling (Jones \& Martin, 1973). Moreover, the EY protects spermatozoa during chilling and freezing by its attachment to the sperm plasma membrane by coating the cell membrane (Watson, 1975). This cryoprotective action is due to the specific binding of lipoproteins present in the EY to the sperm membrane (Watson, 1981; Cookson et al., 1984). High concentrations of EY are successfully used in semen extenders from domestic sheep (Álvarez et al., 2012). In contrast, low EY concentrations are usually used as additives in extenders from wild small ruminant species, such as ibexes (Santiago-Moreno et al., 2006) or ejaculated sperm from mouflon (Pradiee et al., 2017). It is hypothesised that mouflon epididymal sperm might require higher EY concentrations like domestic phylogenetic descendants. The objective of the present work was to study the effect of different concentrations of EY ( $6 \%$ and $12 \% \mathrm{v} / \mathrm{v})$ on mouflon epididymal sperm cryosurvival.

\section{Material and methods}

Epididymal sperm samples were collected from 29 mouflons legally hunted in their natural habitat in the Andalusian hunting reserve of Cazorla and Segura (Jaén, Spain). Sperm collection and cryopreservation were performed in January (at the end of the rutting season) through two different hunting seasons in two consecutive years. Epididymal sperm was collected within $12 \mathrm{~h}$ postmortem. Sperm samples were flushed out with $1 \mathrm{~mL}$ of medium containing Tris $(95.8 \mathrm{mM})$, TES $(210.6 \mathrm{mM})$, glucose $(10.1 \mathrm{mM})$ and either $6 \%$ $\mathrm{v} / \mathrm{v}(\mathrm{n}=16)$ or $12 \% \mathrm{v} / \mathrm{v}(\mathrm{n}=13)$ of clarified EY (prepared by centrifugation and filtration). Chemicals were purchased from Panreac Química S.A. (Barcelona, Spain) and Sigma Chemical Co. (St. Louis, Mo, USA). The osmolality was $320 \mathrm{mOsm} / \mathrm{kg}$ and the $\mathrm{pH}$ 6.8. After 1 hour of equilibration at $5^{\circ} \mathrm{C}$, glycerol was added to a final concentration of $5 \%(\mathrm{v} / \mathrm{v})$ and sperm concentration was adjusted to $800 \cdot 10^{6}$ sperm $/ \mathrm{mL}$. Sperm samples with glycerol were maintained another $15 \mathrm{~min}$ at $5^{\circ} \mathrm{C}$, loaded into $0.25 \mathrm{~mL}$ French straws and frozen by placing them into nitrogen vapor for $10 \mathrm{~min}$ before plunging into liquid nitrogen. The following fresh sperm quality parameters were evaluated immediately after collection at the "field" laboratory located next to the hunting area, as previously described (SantiagoMoreno et al., 2006): sperm concentration, subjective motility, plasma membrane integrity, morphological abnormalities and the acrosome integrity. Sperm concentration was calculated with a Neubauer Chamber
(Marienfeld, Lauda-Königshofen, Germany) and subjective motility was assessed using a phase contrast microscope. Plasma membrane integrity was assessed using the hypo-osmotic swelling test (HOST) and the eosin-nigrosin staining technique $(\mathrm{E} / \mathrm{N})$. Morphological abnormalities and the percentage of spermatozoa with intact acrosomes (NAR: normal acrosome ridge) were evaluated in glutaraldehyde fixed samples using phasecontrast microscopy. Sperm samples were thawed at the INIA laboratory in a water bath at $37^{\circ} \mathrm{C}$ for 30 seconds, and the same sperm quality variables were assessed as for fresh samples. In addition, due to equipment availability, sperm motility parameters were assessed by a computer-assisted sperm analysis system (CASA) (Santiago-Moreno et al., 2013) and membrane integrity and acrosome integrity were evaluated by fluorescence microscopy using the fluorochrome combination of propidium iodide (PI) and fluorescein isothiocyanateconjugated peanut (Arachis hypogaea) agglutinin (PNA-FITC) (Soler et al., 2005). The statistical analysis was performed using Statistica v.12.0 software (StatSoft, Tulsa, OK, USA). Data did not follow a normal distribution therefore were analyzed by the non-parametric Mann-Whitney U-test for unmatched samples. Statistical results were confirmed also by ANOVA analysis of the transformed data.

\section{Results and discussion}

Fresh sperm quality parameters did not differ between groups (Table 1) except for the percentage of NAR that was higher in fresh samples cryopreserved with $12 \%$ EY $(p<0.05)$. Results in Table 2 show that membrane integrity assessed by fluorescence and by the $\mathrm{E} / \mathrm{N}$ technique was higher $(p<0.05)$ in frozenthawed samples cryopreserved with $6 \%$ EY than $12 \%$ EY. Total motility, progressive motility, curvilinear velocity (VCL), straight-line velocity (VSL), average path velocity (VAP) and amplitude of lateral head

Table 1. Fresh sperm quality parameters of mouflon epididymal spermatozoa (mean \pm S.E).

\begin{tabular}{lccc}
\hline & TEST-6\% EY & TEST-12\% EY & $\boldsymbol{p}$ value \\
\hline Motility (\%) & $74.4 \pm 3.8$ & $72.5 \pm 6.6$ & 0.436 \\
$\begin{array}{l}\text { Morphological } \\
\text { abnormalities }\end{array}$ & $12.7 \pm 2.5$ & $10.4 \pm 1.4$ & 0.774 \\
$(\%)$ & & & \\
HOST (\%) & $85.0 \pm 2.9$ & $84.2 \pm 3.3$ & 0.964 \\
NAR (\%) & $88.9 \pm 2.1$ & $94.7 \pm 0.8$ & 0.011 \\
E/N (\%) & $83.2 \pm 1.5$ & $83.7 \pm 1.8$ & 0.982 \\
\hline
\end{tabular}

EY: egg yolk. HOST: hypo-osmotic swelling test. NAR: normal acrosome ridge. E/N: eosin-nigrosin. 
Table 2. Frozen-thawed sperm quality parameters of mouflon epididymal spermatozoa (mean \pm S.E).

\begin{tabular}{lrrc}
\hline & TEST-6\% EY & TEST-12\% EY & $\boldsymbol{p}$ value \\
\hline Membrane integrity (PI) & $31.6 \pm 4.6$ & $11.6 \pm 4.5$ & 0.002 \\
Acrosome integrity (PNA) & $85.1 \pm 3.3$ & $91.9 \pm 2.3$ & 0.147 \\
Motility parameters (CASA) & & & \\
$\quad$ Total motility (\%) & $32.8 \pm 4.6$ & $17.2 \pm 5.6$ & 0.018 \\
Progressive motility $(\%)$ & $13.3 \pm 2.7$ & $6.1 \pm 2.9$ & 0.012 \\
VCL $(\mu \mathrm{m} / \mathrm{s})$ & $103.6 \pm 9.5$ & $70.6 \pm 8.9$ & 0.013 \\
VSL $(\mu \mathrm{m} / \mathrm{s})$ & $58.5 \pm 5.9$ & $38.0 \pm 5.7$ & 0.016 \\
VAP $(\mu \mathrm{m} / \mathrm{s})$ & $84.3 \pm 8.1$ & $55.9 \pm 7.8$ & 0.014 \\
ALH $(\mu \mathrm{m})$ & $2.8 \pm 0.2$ & $1.9 \pm 0.3$ & 0.010 \\
Morphological abnormalities $(\%)$ & $34.0 \pm 3.7$ & $29.1 \pm 3.6$ & 0.496 \\
HOST $(\%)$ & $45.2 \pm 4.5$ & $37.8 \pm 4.5$ & 0.356 \\
NAR $(\%)$ & $60.6 \pm 4.9$ & $60.5 \pm 4.7$ & 0.877 \\
E/N $(\%)$ & $42.9 \pm 4.5$ & $20.9 \pm 6.1$ & 0.005 \\
\hline EY: $(\% g$ ) & & & \\
\hline
\end{tabular}

EY: egg yolk. PI: propidium iodide. PNA: peanut (Arachis hypogaea) agglutinin. CASA: computer-assisted sperm analysis. VCL: curvilinear velocity. VSL: straight-line velocity. VAP: average path velocity. ALH: amplitude of lateral head displacement. HOST: hypo-osmotic swelling test. NAR: normal acrosome ridge. $\mathrm{E} / \mathrm{N}$ : eosin-nigrosin.

displacement (ALH) were also higher in frozen-thawed sperm with $6 \%$ EY than with $12 \%$ EY $(p<0.05)$. The percentage of sperm with morphological abnormalities and with acrosome integrity did not differ between extenders. The membrane integrity assessed by the HOST did not differ between extenders although the presence of coiled tails could have interfered in the counting and interpretation of the results.

The addition of EY on epididymal sperm extenders has a protective effect from cold shock and freezingthawing (Dong \& VandeVoort, 2009; Jimenez et al., 2013). However, different results have been reported regarding the optimum concentration of EY in freezing extenders. Previous studies in Iberian ibex reported higher fertility with epididymal sperm samples frozen in TCG (Tris, citric acid, glucose)-6\% EY than for those extended with TCG-20\% EY (Santiago-Moreno et al., 2006). In agreement with these results, we obtained better freezability of mouflon epididymal sperm samples with freezing extender containing $6 \%$ EY than 12\% EY. Nevertheless other studies obtained better results with high concentrations of EY. Fernández-Sántos et al. (2006) reported more vigorous post-thaw motility of red deer epididymal spermatozoa with $20 \%$ EY than with lower concentrations. Also, Álvarez et al. (2012) reported better post-thaw quality of ram spermatozoa with $20 \%$ EY both in epididymal and ejaculated sperm. The protective effect of EY is influenced by the sperm origin due to the fact that the phospholipid composition and the membrane properties differ between ejaculated and epididymal sperm (Scott et al., 1967). Moreover, the interaction of the EY with the seminal plasma components seems to have a key role on its cryoprotective effect. Ferreira et al. (2014) reported higher post-thaw motility with 5\% EY than with 10\% EY in goat ejaculated sperm without seminal plasma while, with seminal plasma, the postthaw motility was higher with $10 \% \mathrm{EY}$. The effect of EY concentration on ejaculated sperm cryosurvival differs between species and studies. Sperm cooling and freezability of ejaculated sperm was improved with high concentration of $\mathrm{EY}$ in domestic small ruminants (Cabrera et al., 2005; Forouzanfar et al., 2010; Rajabi-Toustani et al., 2014; Şen et al., 2015). On the contrary, increasing concentrations of EY resulted in detrimental effects on post-thaw ejaculated sperm parameters in other species such as gazelles (Holt et al., 1996; Garde et al., 2008). High proportions of EY increase the incidence of acrosomal damage in ram (Watson \& Martin, 1975). Nonetheless, increasing EY concentration did not render any benefit on postthaw sperm quality parameters in bucks (Ustuner et al., 2009) and rhesus macaques (Dong \& VandeVoort, 2009). It has been suggested that these differences could be related with the buffer system used (Watson, 1976; Garde et al., 2008).

In conclusion, the optimum concentration of EY in sperm cryopreservation extenders should be adapted to the protocol, species and sperm origin. There is a maximum concentration of EY above which it has 
detrimental effects on sperm freezability, therefore we recommend the use of a TEST-6\% EY semen extender for mouflon epididymal sperm cryopreservation.

\section{Acknowledgements}

The authors would like to thank the Parque Natural Sierras de Cazorla, Segura y las Villas (Consejería de Medio Ambiente y Ordenación del Territorio, Junta de Andalucía) for the provision of biological samples and its help in implementing the projects proposed.

\section{References}

Álvarez M, Tamayo-Canul J, Martinez-Rodriguez C, Lopez-Uruena E, Gomes-Alves S, Anel L, MartinezPastor F, de Paz P, 2012. Specificity of the extender used for freezing ram sperm depends of the spermatozoa source (ejaculate, electroejaculated or epididymis). Anim Reprod Sci 132 (3-4): 145-154. https://doi.org/10.1016/j. anireprosci.2012.05.006

Bergeron A, Crête M-H, Brindle Y, Manjunath P, 2004. Low-density lipoprotein fraction from hen's egg yolk decreases the binding of the major proteins of bovine seminal plasma to sperm and prevents lipid efflux from the sperm membrane. Biol Reprod 70 (3): 708-717. https://doi.org/10.1095/biolreprod.103.022996

Cabrera F, Gonzalez F, Batista M, Calero P, Medrano A, Gracia A, 2005. The effect of removal of seminal plasma, egg yolk level and season on sperm freezability of canary buck (Capra hircus). Reprod Domest Anim 40 (3): 191195. https://doi.org/10.1111/j.1439-0531.2005.00544.x

Cookson AD, Thomas AN, Foulkes JA, 1984. Immunochemical investigation of the interaction of egg-yolk lipoproteins with bovine spermatozoa. J Reprod Fertil 70 (2): 599-604. https://doi.org/10.1530/ jrf.0.0700599

Dong Q, VandeVoort CA, 2009. Effect of egg yolk on cryopreservation of rhesus monkey ejaculated and epididymal sperm. J Androl 30 (3): 309-316. https://doi. org/10.2164/jandrol.108.006395

Fernandez-Santos MR, Esteso MC, Montoro V, Soler AJ, Garde JJ, 2006. Cryopreservation of Iberian red deer (Cervus elaphus hispanicus) epididymal spermatozoa: Effects of egg yolk, glycerol and cooling rate. Theriogenology 66 (8): 1931-1942. https://doi. org/10.1016/j.theriogenology.2006.05.012

Ferreira VdS, Mello MRBd, Fonseca CEMd, Dias ÁCF, Cardoso JM, Silva RB, Martins Júnior WP, 2014. Effect of seminal plasma and egg yolk concentration on freezability of goat semen. R Bras Zootec 43 (10): 513-518. https:// doi.org/10.1590/S1516-35982014001000001
Forouzanfar M, Sharafi M, Hosseini SM, Ostadhosseini S, Hajian M, Hosseini L, Abedi P, Nili N, Rahmani HR, Nasr-Esfahani MH, 2010. In vitro comparison of egg yolk-based and soybean lecithin-based extenders for cryopreservation of ram semen. Theriogenology 73 (4): 480-487. https://doi.org/10.1016/j.theriogenology.2009.10.005

Garde JJ, del Olmo A, Soler AJ, Espeso G, Gomendio M, Roldan ERS, 2008. Effect of egg yolk, cryoprotectant, and various sugars on semen cryopreservation in endangered Cuvier's gazelle (Gazella cuvieri). Anim Reprod Sci 108 (3-4): 384-401. https://doi.org/10.1016/j. anireprosci.2007.09.010

Holt WV, Abaigar T, Jabbour HN, 1996. Oestrous synchronization, semen preservation and artificial insemination in the Mohor gazelle (Gazella dama mhorr) for the establishment of a genome resource bank programme. Reprod Fertil Dev 8 (8): 1215-1222. https:// doi.org/10.1071/RD9961215

Jimenez E, Perez-Marin CC, Vizuete G, Millan Y, Aguera EI, 2013. Effect of different extenders on in vitro characteristics of feline epididymal sperm during cryopreservation. Reprod Domest Anim 48 (4): 665-672. https://doi.org/10.1111/rda.12142

Jones RC, Martin IC, 1973. The effects of dilution, egg yolk and cooling to $5^{\circ} \mathrm{C}$ on the ultrastructure of ram spermatozoa. J Reprod Fertil 35 (2): 311-320. https://doi. org/10.1530/jrf.0.0350311

Manjunath P, 2012. New insights into the understanding of the mechanism of sperm protection by extender components. Anim Reprod 9 (4): 809-815.

Pradiee J, Esteso MC, Castaño C, Toledano-Díaz A, LópezSebastián A, Guerra R, Santiago-Moreno J, 2017. Conventional slow freezing cryopreserves mouflon spermatozoa better than vitrification. Andrologia 49: e12629. https://doi.org/10.1111/and.12629

Rajabi-Toustani R, Roostaei-Ali Mehr M, MotamediMojdehi R, 2014. Effect of different levels of egg yolk on ram sperm coating and preserving at $5 \mathrm{C}$. Iran J Vet Res 15 (2): 168-171.

Santiago-Moreno J, Toledano-Diaz A, Pulido-Pastor A, Dorado J, Gomez-Brunet A, Lopez-Sebastian A, 2006. Effect of egg yolk concentration on cryopreserving Spanish ibex (Capra pyrenaica) epididymal spermatozoa. Theriogenology 66 (5): 1219-1226. https:// doi.org/10.1016/j.theriogenology.2006.03.031

Santiago-Moreno J, Castano C, Toledano-Diaz A, Esteso MC, Lopez-Sebastian A, Guerra R, Ruiz MJ, Mendoza N, Luna C, Cebrian-Perez JA, et al., 2013. Cryopreservation of aoudad (Ammotragus lervia sahariensis) sperm obtained by transrectal ultrasoundguided massage of the accessory sex glands and electroejaculation. Theriogenology 79 (2): 383-391. https://doi.org/10.1016/j.theriogenology.2012.10.011 
Scott TW, Voglmayr JK, Setchell BP, 1967. Lipid composition and metabolism in testicular and ejaculated ram spermatozoa. The Biochem J 102 (2): 456-461. https://doi.org/10.1042/bj1020456

Şen ÇÇ, Tekin K, Akçay E, 2015. Effect of egg yolk and removal of seminal fluid on semen cryopreservation in Norduz goat. Harran Üniv Vet Fak Derg 4 (2): 64-67.

Soler AJ, Esteso MC, Fernandez-Santos MR, Garde JJ, 2005. Characteristics of Iberian red deer (Cervus elaphus hispanicus) spermatozoa cryopreserved after storage at 5 degrees $\mathrm{C}$ in the epididymis for several days. Theriogenology 64 (7): 1503-1517. https://doi. org/10.1016/j.theriogenology.2005.03.013

Ustuner B, Gunay U, Nur Z, 2009. Effect of seminal plasma, egg yolk, and season on the freezability of Saanen buck semen. Bull Vet Inst Pulawy 53: 369-374.
Watson PF, 1975. The interaction of egg yolk and ram spermatozoa studied with a fluorescent probe. J Reprod Fertil 42 (1): 105-111. https://doi.org/10.1530/ jrf.0.0420105

Watson PF, 1976. Electroejaculation, semen characteristics and semen preservation of the brindled gnu. J Reprod Fertil 47 (1): 123-126. https://doi.org/10.1530/jrf. 0.0470123

Watson PF, 1981. The roles of lipid and protein in the protection of ram spermatozoa at 5 degrees $\mathrm{C}$ by eggyolk lipoprotein. J Reprod Fertil 62 (2): 483-492. https:// doi.org/10.1530/jrf.0.0620483

Watson PF, Martin IC, 1975. Effects of egg yolk, glycerol and the freezing rate on the viability and acrosomal structures of frozen ram spermatozoa. Aust J Biol Sci 28 (2): 153-159. https://doi.org/10.1071/BI9750153 